\title{
Collagen-based materials in reproductive medicine and engineered reproductive tissues
}

\author{
Hanxiao Chen ${ }^{1,2,3+}$, Luqi Xue ${ }^{1,2+}$, Guidong Gong ${ }^{4 \dagger}$, Jiezhou Pan ${ }^{4}$, Xiaoling Wang ${ }^{4}$, Yaoyao Zhang ${ }^{1,2^{*}}$, \\ Junling Guo ${ }^{4,5^{*}}$ and Lang Qin ${ }^{1,2^{*}}$
}

\begin{abstract}
Collagen, the main component of mammal skin, has been traditionally used in leather manufacturing for thousands of years due to its diverse physicochemical properties. Collagen is the most abundant protein in mammals and the main component of the extracellular matrix (ECM). The properties of collagen also make it an ideal building block for the engineering of materials for a range of biomedical applications. Reproductive medicine, especially human fertility preservation strategies and reproductive organ regeneration, has attracted significant attention in recent years as it is key in resolving the growing social concern over aging populations worldwide. Collagen-based biomaterials such as collagen hydrogels, decellularized ECM (dECM), and bioengineering techniques including collagen-based 3D bioprinting have facilitated the engineering of reproductive tissues. This review summarizes the recent progress in applying collagen-based biomaterials in reproductive. Furthermore, we discuss the prospects of collagen-based materials for engineering artificial reproductive tissues, hormone replacement therapy, and reproductive organ reconstruction, aiming to inspire new thoughts and advancements in engineered reproductive tissues research.
\end{abstract}

Keywords: Collagen-based biomaterials, Leather and collagen, Leather tanning process, Reproductive medicine, Reproductive tissues

\footnotetext{
*Correspondence: yaoyaozhang@scu.edu.cn; junling.guo@scu.edu.cn; cacier@163.com

${ }^{\dagger}$ Hanxiao Chen, Luqi Xue and Guidong Gong have contributed equally to this work

1 Department of Obstetrics and Gynecology, The Reproductive Medical

Center, West China Second University Hospital, Sichuan University,

Chengdu 610041, China

${ }^{4}$ BMI Center for Biomass Materials and Nanointerfaces, College

of Biomass Science and Engineering, Sichuan University,

Chengdu 610065, Sichuan, China

Full list of author information is available at the end of the article
}

\section{Springer Open}

(c) The Author(s) 2022. Open Access This article is licensed under a Creative Commons Attribution 4.0 International License, which permits use, sharing, adaptation, distribution and reproduction in any medium or format, as long as you give appropriate credit to the original author(s) and the source, provide a link to the Creative Commons licence, and indicate if changes were made. The images or other third party material in this article are included in the article's Creative Commons licence, unless indicated otherwise in a credit line to the material. If material is not included in the article's Creative Commons licence and your intended use is not permitted by statutory regulation or exceeds the permitted use, you will need to obtain permission directly from the copyright holder. To view a copy of this licence, visit http://creativecommons.org/licenses/by/4.0/. 


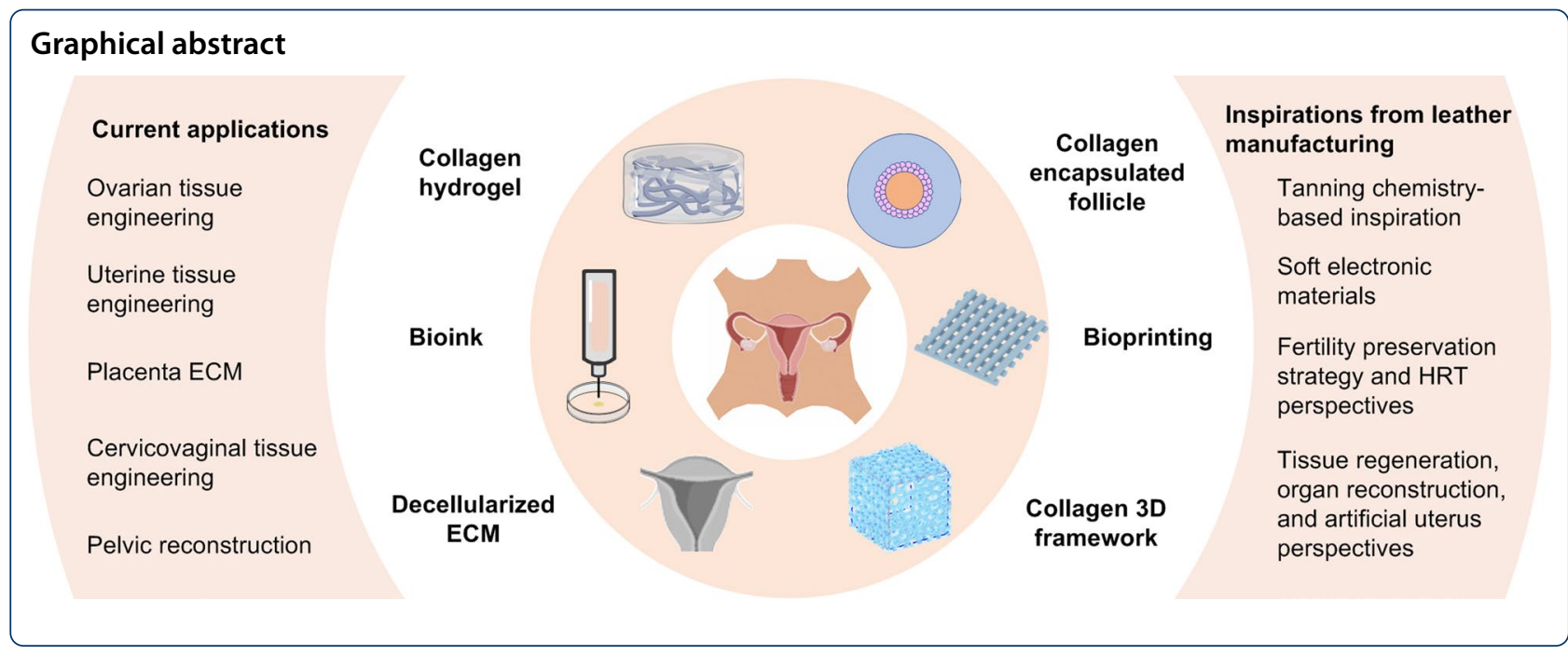

\section{Introduction}

Collagen is an important renewable resource that has been used for thousands of years in leather manufacturing. To turn animal hide into wearable leather, a complex and scientific preparation process is required, where plant tannins or metal ions are used to crosslink the active groups in collagen fibers. This process creates a more porous internal microstructure, reduces the bonds between collagen fibers, reduces leather expansion in water, improves the moisture and heat resistance, and also improves the chemical corrosion resistance [1]. Additionally, the processes and materials used in leather making can provide fundamental inspiration and guidelines for further developing biomaterials based on collagen or collagen derivatives (e.g., gelatin) [2]. So far, more than 29 types of collagen molecules have been identified and studied, which together provide a powerful toolbox for the preparation of multifunctional biomaterials [3]. Due to the high biocompatibility and versatile chemical properties, collagen has been widely used in the preparation of biomaterials and the treatment of various diseases [4].

One of the most concerning issues for societies around the world is population aging. Recent environmental and social structural changes have led to the rapid decline of human fertility and accelerated the global demographics shift towards an aging population. Population aging tends to lower both labor-force participation and savings rates, which together raise concerns about slowing economic growth in the future. Though behavioral responses (for example, greater female labor-force participation) and policy reforms (for example, an increase in the legal age of retirement) can mitigate the economic consequences of an older population, the key to resolving the growing issue of population aging in a sustainable future is to increase fertility rates and birthrates. Currently, around $8-12 \%$ of reproductive-aged couples suffer from infertility worldwide, of which women contribute to approximately half of the cases [5]. Over the past few decades, reproductive medicine has developed rapidly, with the introduction of in vitro fertilization (IVF) in 1978 [6], the cryopreservation of human oocytes in 1986 [7], intracytoplasmic sperm injection (ICSI) in 1992 [8], and the in vitro maturation (IVM) of oocytes in 1994 [9]. Meanwhile, there has also been remarkable progress in the transplantation of reproductive organs, including ovary [10], uterus [11], and vagina [12] transplantation. Novel materials engineering approaches are needed to facilitate continued progress in this space and collagenbased biomaterials have been applied in the recovery and regeneration of injured or damaged reproductive tissue [13] and contraception [14, 15].

In this review, we aim to comprehensively summarize and discuss the current progress and future possibilities of collagen-based materials for reproductive medicine (Fig. 1). Besides, gelatin, a derivative of collagen generated through hydrolyzing the natural triple-helix structure into single-strand polypeptides, is included in this review due to its collagen-like properties and high potential in tissue engineering. This review highlights the interfaces between regenerative biomaterials and traditional leather science. Since collagen and tanning chemistry have been used throughout human history for thousands of years, the experience and techniques from leather science can provide fundamental guidelines and inspiration for the design and engineering of the next generation of reproductive biomaterials. 


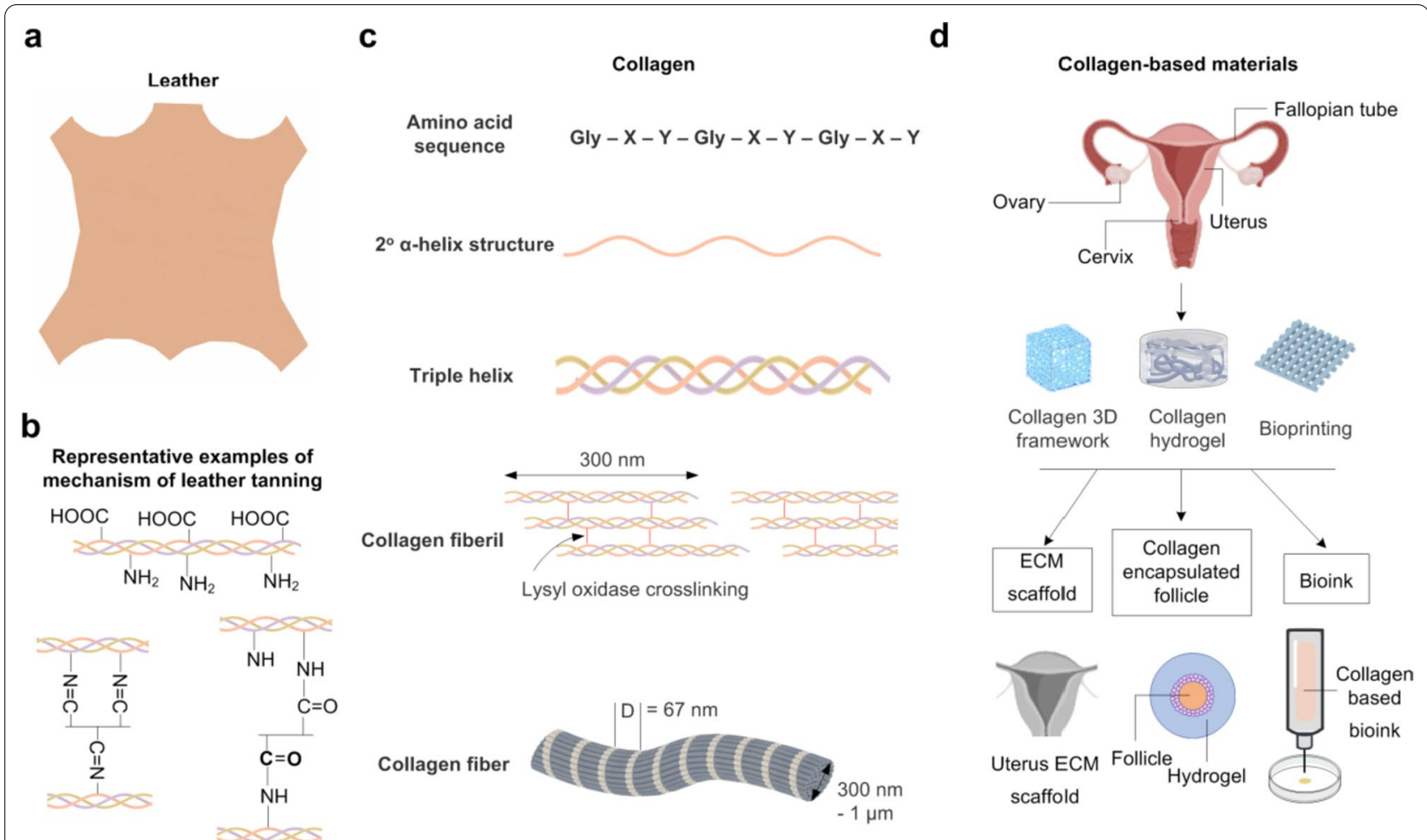

Fig. 1 a, b Illustration of leather and representative examples of leather tanning mechanisms. c Schematic drawing of the hierarchical structures of collagen [19]. Reproduced with permission from [19]. d Collagen-based materials and their use in reproductive medicine

\section{Collagen-based materials in reproductive medicine}

Collagen protein has a highly complex and hierarchical conformation, which is organized as a quaternary structure, where a triple helix super secondary structure is the most defining feature of collagen (Fig. 1c). The primary structure of collagen is characterized by the fixed presence of glycine (Gly), which is found in every amino acid triplet. Proline (Pro) and hydroxyproline (Hyp) are also frequently found, as Gly-Pro-Hyp is the most common sequence in collagen (approximately 12\%). Additionally, Gly-X-Hyp and Gly-Pro-Y sequences together account for another $44 \%$ of sequences with the remaining $44 \%$ being Gly-X-Y sequences [16]. The $\alpha$-chains are formed by repetitions of the tripeptide, with a triple-helical domain in the middle, and two non-helical domains at either end of the helix. Three parallel $\alpha$ polypeptide chains coil around each other to form the triple helix structure, which is approximately $300 \mathrm{~nm}$ in length and $1.5 \mathrm{~nm}$ in diameter and is the fundamental structure of collagen $[17,18]$. Collagen fibrils are formed by the selfassembly of collagen molecules through a quarter-stagger package pattern of five triple-helical collagen molecules, where the overlap and gap regions between these collagen molecules result in the $\sim 67 \mathrm{~nm}$ D-periodicity of collagen fibers [17]. Here, we outline some major models and applications of collagen-based materials in reproductive medicine. We aim to provide a clear understanding of the benefits of collagen-based materials so that there can be further improvement in reproductive tissue engineering.

\subsection{Collagen hydrogel scaffolds}

Hydrogels are three-dimensional (3D) polymer network structures with high water content, in which the polymer chain maintains structural integrity through physical and chemical crosslinking. Hydrogels are widely used in biotechnology and medicine to deliver cells, drugs, or biologically active molecules, and are also regularly used in cell culture. Cells can be cultured atop a two-dimensional (2D) hydrogel or embedded in a hydrogel as a more complex 3D culture system [20]. Collagen hydrogel is one of the most used naturally derived hydrogels owing to its physical, mechanical, and biological properties. Collagen hydrogels have high water content (over 99\%) and demonstrate the ability to gel, swell, self-aggregate, and can be enzymatically degraded [21]. Moreover, they can provide a relatively realistic microenvironment mimic ECM, which allows cell adhesion, proliferation, differentiation, and protein sequestration. However, collagen hydrogels 
are not always ideal as scaffold materials because of their weak mechanical strength due to rapid degradation rate in biological environments, opacity, and high shrinkage [22]. It is therefore often necessary to improve the overall performance of collagen hydrogels for tissue engineering.

Crosslinking collagen with other materials (e.g., chitosan [23], polyvinyl alcohol [24], alginate [25], hyaluronic acid [26], polyethylene glycol [27], and fibrin [28]) can significantly enhance the mechanical and biological stability of collagen hydrogels. In addition, gelatin is a derivative of collagen generated through heat or chemical treatment [29] via hydrolyzing the natural triple-helix structure into a single-strand polypeptide. Gelatin retains the cell-binding regions and the biological properties of collagen and is highly water-soluble, biocompatible, biodegradable, and has low immunogenicity $[30,31]$ making it promising in tissue engineering. To date, there have been many attempts to utilize collagen hydrogels in reproductive medicine and tissue engineering. For example, one study encapsulated the telomerase immortalized human endometrial stromal cells in a collagen I hydrogel and treated it with in vitro hormone exposures. The results suggested that the engineered endometrial stroma could mimic the natural morphological and biochemical changes occurring during secretory and menstrual phases of the menstrual cycle [32]. Another study cultured ovarian follicles in collagen I hydrogel and found that the density and elasticity of the hydrogel could influence follicle survival, growth, development, and hormone production, along with oocyte maturation and ovulation [33]. One study applied a gelatin hydrogel, specifically a pue-loaded gelatin methacrylate (Pue@GelMA) hydrogel, in pelvic organ prolapse (POP) models. This material could alleviate inflammation by reducing the level of inflammatory factors and accelerating the reconstruction and regeneration of the pelvic floor fascia [34]. Still, other studies have reported that transplantation of stem cells with collagen scaffolds [35] or the transplantation of encapsulated autograft ovarian tissue fragments in fibrincollagen hydrogels [36] helps ovarian survival and recovery. Therefore, collagen hydrogels can be utilized in many fields, including in vitro 3D tissue culture, and the reconstruction and transplantation of reproductive tissues and organs.

\subsection{Decellularized ECM}

ECM generally refers to the non-cellular substances surrounding the cells in tissues or organs, and mainly consists of structural substances (e.g., collagen, elastin, polysaccharides, and proteoglycans) and functional molecules (e.g., growth factors, cytokines, chemokines). ECM plays an essential role in cell proliferation, differentiation, maturation, cell communication, homeostasis, immunity, and many other biological processes [37]. dECM can be obtained by removing the cellular components of tissues or organs while retaining the 3D structural and biochemical components of the ECM [38]. Different methods can be used to process $\mathrm{dECM}$, including mechanical, chemical, and enzymatic treatment [38]. Moreover, dECM can be modified by physical and chemical crosslinking using chemical crosslinking agents (e.g., carbodiimide (CDI), epoxy compounds, glutaraldehyde, and hexamethylene diamine carbamate (HMDC)) and natural (e.g., genipin (GP), tannic acid, proanthocyanins (PC), and nordihydroguaiaretic acid (NDGA)) crosslinking agents [39-41] to generate various materials (e.g., powders, patches, and hydrogels) [38]. Some consider AECM to be the best choice for tissue engineering among different hydrogels because it has the natural structure and composition of individual tissue and can thus facilitate reseeding cells and cellular reorganization [42].

dECM has been widely applied to engineer reproductive tissue and retain its structure and function. For example, culturing ovarian cells onto the dECM scaffold allows cells to reconstruct follicle-like structures, produce hormones, and even initiate puberty after transplantation, thus preserving and reestablishing female fertility [43-53]. For uterus engineering, decellularized endometrial tissue has been repopulated with endometrial cells successfully, where the viability, proliferation, and hormonal response of endometrial cells have been restored [44, 54-67]. The decellularization of the placentas also has extensive applications in regenerative and reproductive medicine [68-70]. Overall, dECM has been widely applied as a scaffold of choice in reproductive tissue engineering, yet it is challenging to restore the mechanical strength of $\mathrm{dECM}$ and postpone the rapid degradation in vivo while maintaining the structural and biochemical function.

\subsection{Collagen-based bioinks for 3D printing and bioprinting}

Over the past 20 years, 3D printing has been widely applied in biomedicine for medical devices and instruments, and in tissue regeneration, cell culture, and drug discovery and development [71]. 3D printed scaffolds for tissue engineering are porous, polymeric, cell-free scaffolds used for subsequent cell seeding, which are of high accuracy and complexity, and can be produced rapidly $[72,73]$. While 3D printing is a cell-free technology, 3D bioprinting is characterized by using cell-laden 'bioinks' to directly build engineered tissues and organs [74]. 3D bioprinting has various advantages, including geometrical freedom, automation, standardization reproducibility, repeatability, realistic microenvironments, and customizability [75]. Therefore, compared with conventional 
tissue engineering methods, 3D bioprinting can accurately deposit cells and biomaterials together into precisely controlled architectures.

Bioinks are vital for 3D bioprinting because they should contain the necessary conditions to provide both structural and biochemical support for cell viability and growth. Therefore, bioinks need to have high biocompatibility, printability, and low antigenicity. The most common components of bioinks include ECM proteins (e.g., collagen, gelatin), functional molecules (e.g., growth factors, cytokines), and cells [76]. Currently, collagen, gelatin, and ECM hydrogels are extensively used as components of bioinks in 3D bioprinting of different tissues because of their high biocompatibility, printability, and workability. Nevertheless, these biomaterials need to be modified (e.g., crosslinking) and mixed in suitable proportions to improve the mechanical strength and biological properties before being used as bioinks [2].

Recently, there are emerging studies about the application of 3D bioprinting in reproductive medicine. For example, one study used a gelatin bioink scaffold and isolated small follicles to create a bioprosthetic ovary. They found it could survive, be vascularized, and even preserve ovarian function (i.e., ovulation) and fertility after transplantation [77]. Another study used a gelatin/sodium alginate hydrogel as a bioink for 3D bioprinting a human induced pluripotent stem cell (iPSC)-derived mesenchymal stem cell (MSC)-loaded scaffold to regenerate endometrium. This material could improve the recovery of the endometrial histomorphology and aid the regeneration of stromal, epithelial, and endothelial cells. Moreover, this not only enhanced endometrial receptivity but also restored the ability of implantation and pregnancy maintenance of the injured endometrium [78]. Another study successfully applied an acellular vagina matrix (AVM) hydrogel and seaweed gelatin/alginate hydrogel as bioinks in 3D bioprinting biomimetic vaginal tissue, which showed good biocompatibility, vascularization, epithelization, and differentiation [79]. Similarly, 3D bioprinting of collagen-based material bioinks could be utilized for engineering placenta models [80]. Still, there is a long road ahead for 3D bioprinting reproductive tissues and organs, and bioinks based on collagen-based materials have yet to be fully explored.

\section{Current applications of collagen-based biomaterials}

Current applications of collagen-based biomaterials in reproductive medicine and engineered reproductive tissues are extensively summarized in Table 1 . In general, collagen-based biomaterials demonstrate various advantages in the field of reproductive medicine as they can suspend and support isolated reproductive function cells, have high biocompatibility, and are biodegradable in vivo and in vitro.

\subsection{Ovarian tissue engineering using collagen-based biomaterials}

With the development of modern medical technology, the survival period of young cancer patients has been significantly extended, however, chemotherapy and radiation therapy are generally gonadotoxic. Therefore, fertility preservation treatment is necessary for young cancer patients who have not yet had children. Re-transplantation after cryopreservation of ovarian tissue is the only option to preserve fertility in prepubertal female patients who required immediate cancer therapy. In addition, for some fertile female patients, re-transplantation of ovarian tissue can preserve the endocrine function of the ovary to reduce the risk of osteoporosis, cardiovascular disease, and vasomotor symptoms. Meanwhile, patients who suffer from decreased ovarian reserve due to the surgical

Table 1 Overview of recent studies in collagen-based materials in reproductive medicine and engineered reproductive tissues

\begin{tabular}{llll}
\hline Collagen-based material & Tissue & Application & References \\
\hline Hydrogel & Ovary & Follicle encapsulation and culture & {$[33,81-94]$} \\
& Uterus & Endometrial cell culture & {$[95,96]$} \\
& Fallopian tube & 3D organoid culture & {$[97]$} \\
dECM & Ovary & Follicle culture and transplantation & {$[46,47,49,50,98-100]$} \\
& Uterus & Endometrial, myometrial cell culture, and transplantation & {$[55-58,62,66]$} \\
& Placenta & Generate scaffolds & {$[70,101,102]$} \\
Collagen-based bioink & Cervicovaginal & Cervicovaginoplasty & {$[12,13,103-106]$} \\
& Ovary & Follicle culture and transplantation & {$[77]$} \\
& Placenta & Bioengineered placenta model & {$[80,107]$} \\
Collagen coating Mesh & Pelvic floor & Mesh encapsulation and pelvic floor reconstruction & {$[108]$} \\
\hline
\end{tabular}


treatments of benign ovarian tumors and endometriosis could also benefit from fertility preservation treatment.

However, ovarian tissue transplantation faces several problems in clinical practice. The most prominent problem is the risk of disease metastasis and recurrence caused by the potential reintroduction of cancer cells and an initial ischemic injury of ovarian tissue after transplantation [112, 113]. Engineered reproductive tissues provided promising solutions. In the process of ovarian transplantation, any malignant cells should be separated so that only core functional cells are transplanted.

The essential functional component of the ovary is the ovarian follicle in the cortex, and collagen-based materials have been applied to encapsulate ovarian follicles and provide the extracellular support structure for cell growth. The encapsulated oocytes and related somatic cells could successfully survive and secrete hormones in vitro and the mouse transplantation model. The collagen-based bio-materials currently applied for encapsulating follicles are hydrogels primarily comprised of Matrigel (a natural hydrogel secreted by mouse sarcoma cells), alginate (a natural hydrogel derived from algae), and poly(ethylene glycol) (Fig. 2). It has been reported that macroporous alginate scaffolds layered with affinitybound bone morphogenetic protein- 4 could successfully mimic the ovary microenvironment. Porcine primordial follicles could be cultured in these scaffolds to the preantral stage and retain their hormone-secreting function in an immunodeficiency mice xenotransplantation model [93]. Furthermore, isolated ovarian follicles have been seeded in alginate-matrigel matrix scaffolds and transplanted into mice models. After transplantation, the matrix scaffolds were observed to degrade and allowed vascularization around the follicles [91].

During encapsulation and transplantation, hydrogels can exhibit beneficial support for cells. For example, a microfluidic microencapsulation hydrogel encapsulation model was reported to successfully mimic the mechanical characteristics of the mammalian ovary in vitro. A softer $0.5 \%$ collagen hydrogel core mimicked the medulla of the ovary, while a harder, and slowly degradable $2 \%$ alginate hydrogel shell mimicked the rigid cortex of the ovary. This 3D culture model could effectively transport oxygen and nutrients to the capsulated ovarian follicles (Fig. 2). Finally, the controlled degradation of the capsule could be achieved by alginate lyase encapsulated in PLGA microspheres [114].

Other strategies are also promising, including the use of dECM to assist human ovarian tissue auto-re-transplantation. For example, the AECM materials called AlloDerm (LifeCell Corp.) have been applied in human ovarian tissue re-transplantation following cryopreservation. After the re-transplantation, the patient gained IVF live-birth with subsequent hormone secretion until 2-year after transplantation. AlloDerm is a decellularized product derived from cadaveric or xenographic skin that can be used in tissue reconstruction and plastic surgery [115]. It is possible to construct a decellularized human ovarian scaffolds model from ovarian tissue donated by patients with malignant tumors, and by removing all of the cells from the ECM (including malignant cells), the collagen content of the ovary could be preserved (Fig. 3).
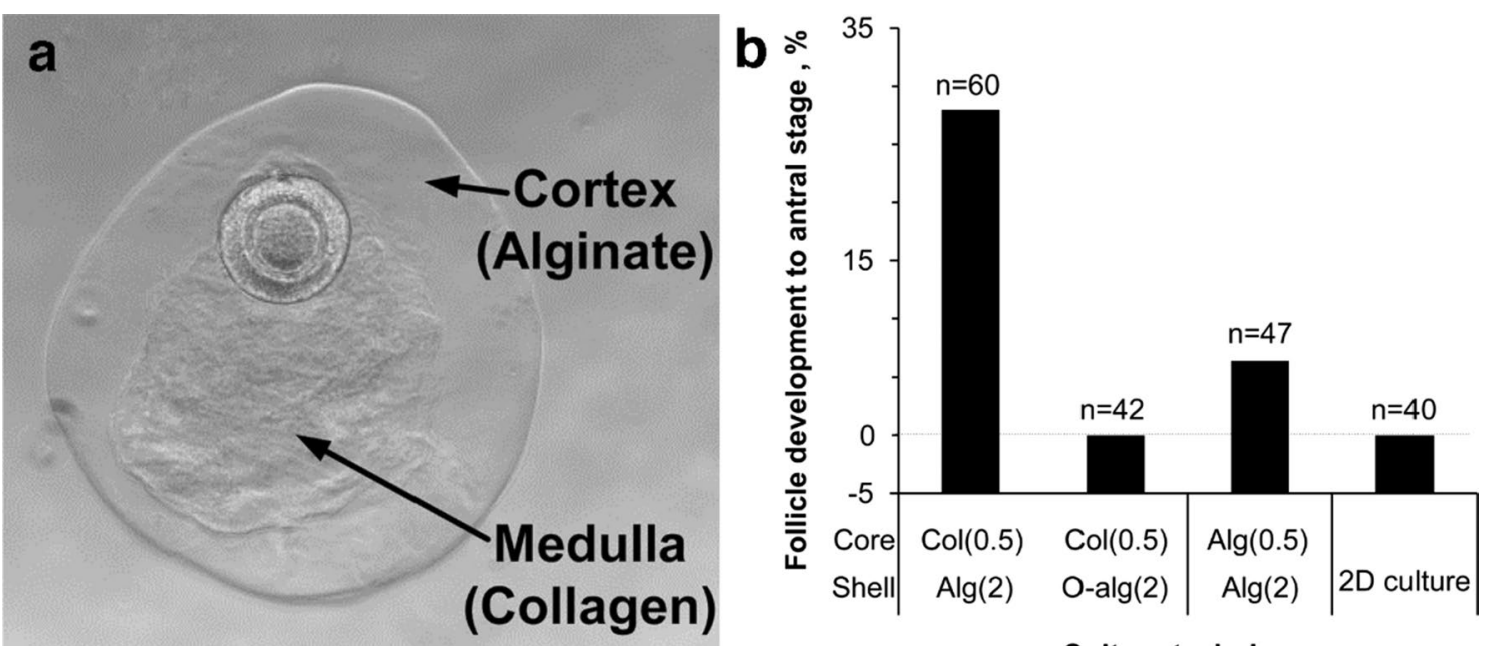

Culture technique

Fig. 2 Collagen-encapsulated follicle. a Micrographs of an early secondary preantral follicle encapsulated in a collagen core with an alginate shell. b Quantitative data shows the effect of the core ( $0.5 \%$ collagen) and shell ( $2 \%$ non-oxidized alginate) materials is the highest. Collagen (Col), alginate (Alg), oxidized-alginate (O-alg). Reproduced with permission from [114] 


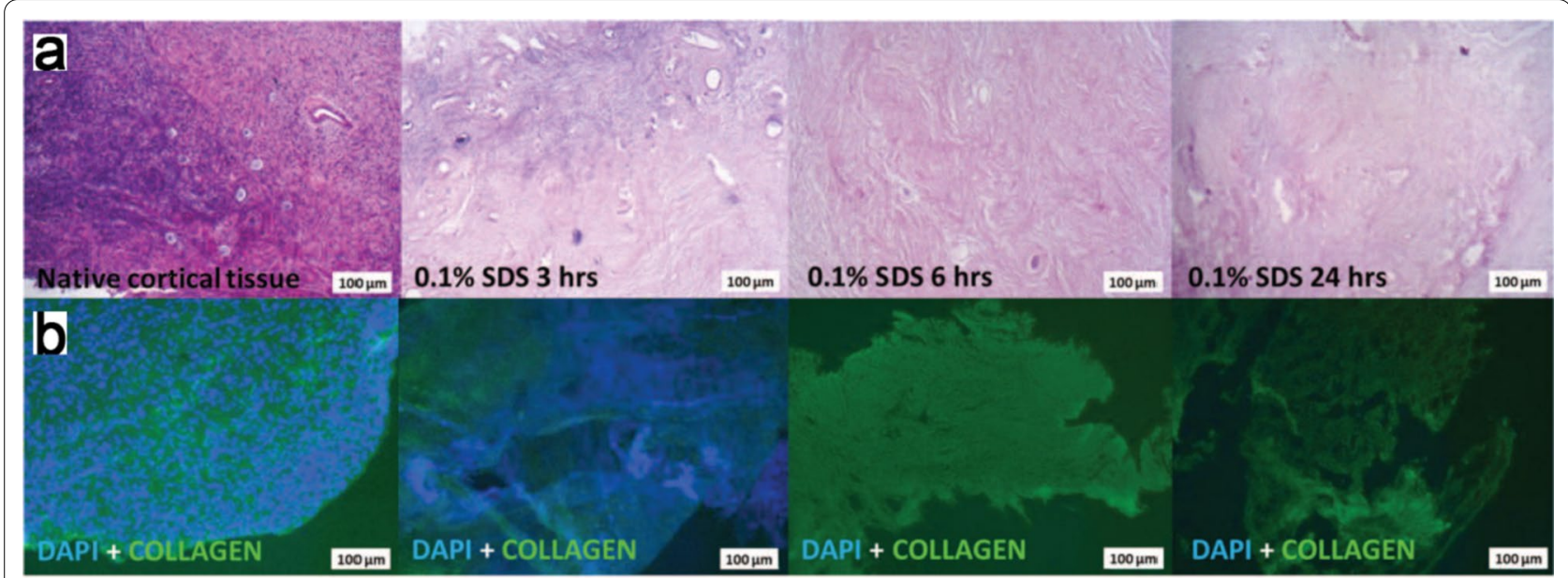

Fig. 3 dECM of human cortical ovarian tissue. a PAS staining of human cortical ovarian tissue. b Immunofluorescent staining (collagen in green and DAPI in blue) of human cortical ovarian tissue. (Periodic Acid-Schiff (PAS) stain is mainly used to detect carbohydrates in tissues; 4,6-diamidino-2-phenylindole (DAPI) is a fluorescent dye that can bind to DNA, which is mainly used for cell staining). Reproduced with permission from [48]

Human ovarian stromal cells and pre-antral follicles could be reseeded to the scaffolds and cultured in vitro and transplanted subcutaneously to immunodeficient mice. As a result, human ovarian stromal cells were observed to recellularize the scaffolds, and about $39 \%$ of pre-antral follicles grew into antral stages without malignancy [48]. It is speculated that all of these AECM models act as a biologic scaffold by assisting epithelialization, neovascularization, and fibroblast infiltration, however, there is limited research into the exact mechanisms, and supporting data is still needed.

The biggest practical drawback of microfluidic hydrogel encapsulation technology is the limited number of follicle cells encapsulated. When applied to large animals and humans, an ideal biological scaffold needs to carry a large number of follicular cells while achieving the vascularization, infiltration of nutrients, discharge of follicles, and secretion of hormones. Emerging additive manufacturing techniques such as 3D printing microporous hydrogel scaffolds (Fig. 4), which serve as pore architecture to encapsulate ovary follicles, are alternative approaches that have facilitated the development of bioengineering. Controlled microporous architectures can be constructed by $3 \mathrm{D}$ printing thermally regulated crosslinked gelatin, where interestingly $60^{\circ}$ angle scaffolds were the most efficient for cell growth and maturation When transplanted to surgically sterilized mice, the artificial 3D printed follicle-seeded scaffolds became highly vascularized and started to ovulate and secrete hormones. Next, the healthy delivery of mice was reported following natural mating [77]. Moreover, Jakus AE et al. elaborated that the $\mathrm{dECM}$ "bioink" from bovine ovarian is usable in $3 \mathrm{D}$ printing (Fig. 5), indicating the 3D printing technology might be promising in future human fertility reservation applications [116].

\subsection{Uterine tissue engineering using collagen-based biomaterials}

The treatment of infertility has been partially resolved with the emergence of IVF technology. However, IVF can only resolve infertility due to fallopian tube and ovulation factors. Surrogacy on the other hand, which is illegal in most countries due to ethical controversy, is currently the only option to resolve absolute uterine infertility (absent or non-functional uterus), which has a prevalence of $3-5 \%$ in all women [117].

Owing to the rapid development of materials in recent years, the exploration of a tissue-engineered artificial uterus offers some hope to patients suffering from uterine infertility. Research on engineering uterine tissue is generally in the exploratory stage and mainly applies recellularized uterine $\mathrm{dECM}$ scaffolds in animal transplantation models. The dECM scaffold is produced by perfusing Triton X-100 and Sodium dodecyl sulfate (SDS)/Dimethyl sulfoxide (DMSO) into the uterus. Immunofluorescence staining of the $\mathrm{dECM}$ scaffold shows that the collagen content remains intact after this process [56], after which recellularization procedures can be achieved by injecting stem cells into dECM scaffolds. In a pilot study, the uterine epithelial cells were artificially migrated into a dECM scaffold. The modified scaffold was transplanted into an artificially defective murine uterus. An intact epithelial layer formed and the migration and regeneration of myometrial and stroma cells were observed sequentially, 

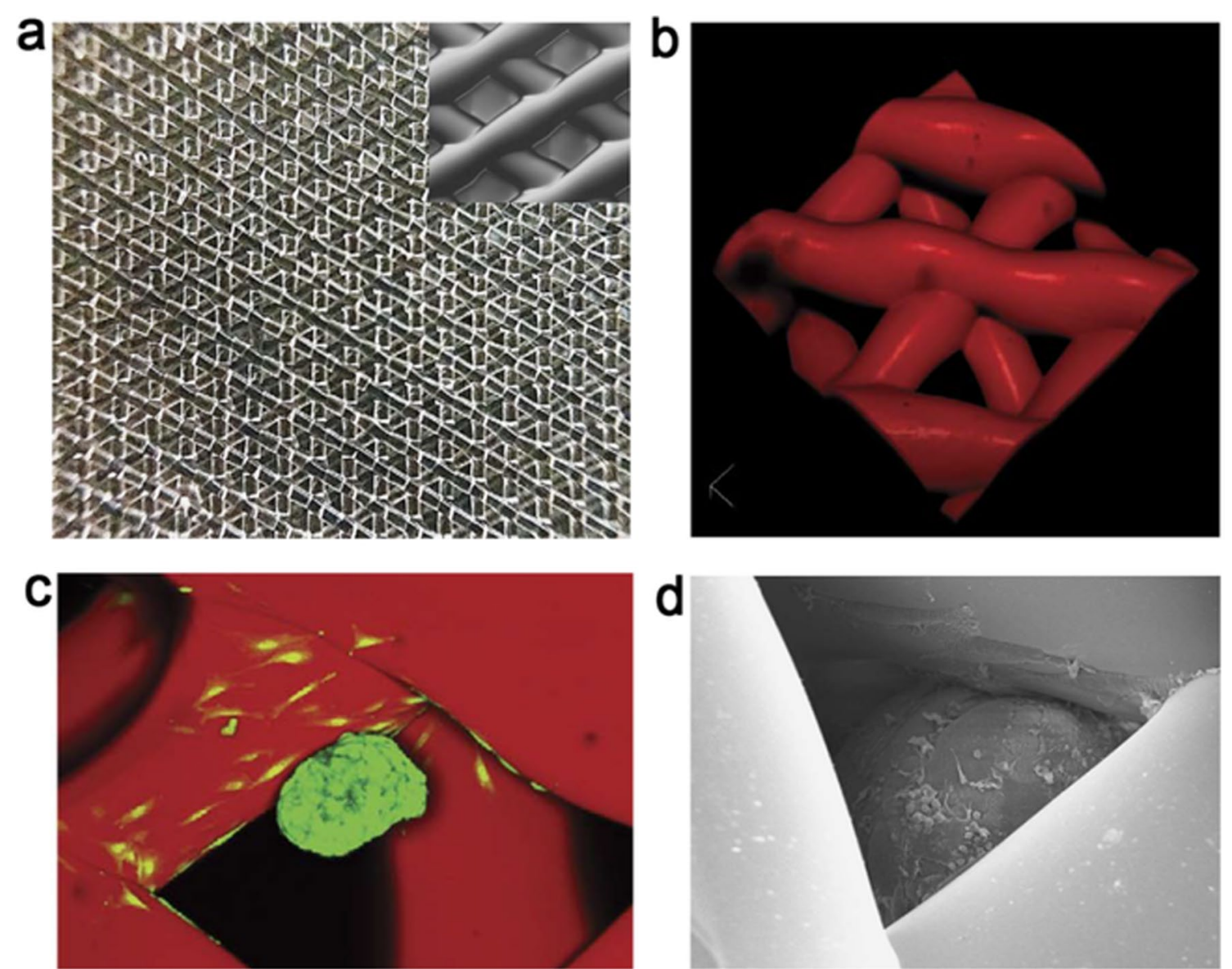

Fig. 4 Ovarian follicles cultured in 3D printed microporous gelatin scaffolds. a Macroscopic view of 3D printed microporous gelatin five-layered scaffolds printed with a $100 \mathrm{~mm}$ nozzle. b 3D reconstructions of a confocal fluorescence image of $60^{\circ}$ angle gelatin scaffolds. c Confocal fluorescence image of follicles seeded in pores after 2 days of culture. $\mathbf{d}$ Electron micrograph of an ovarian follicle wedged underneath $60^{\circ}$ angle gelatin scaffolds after 2 days of culture. Reproduced with permission from [77]

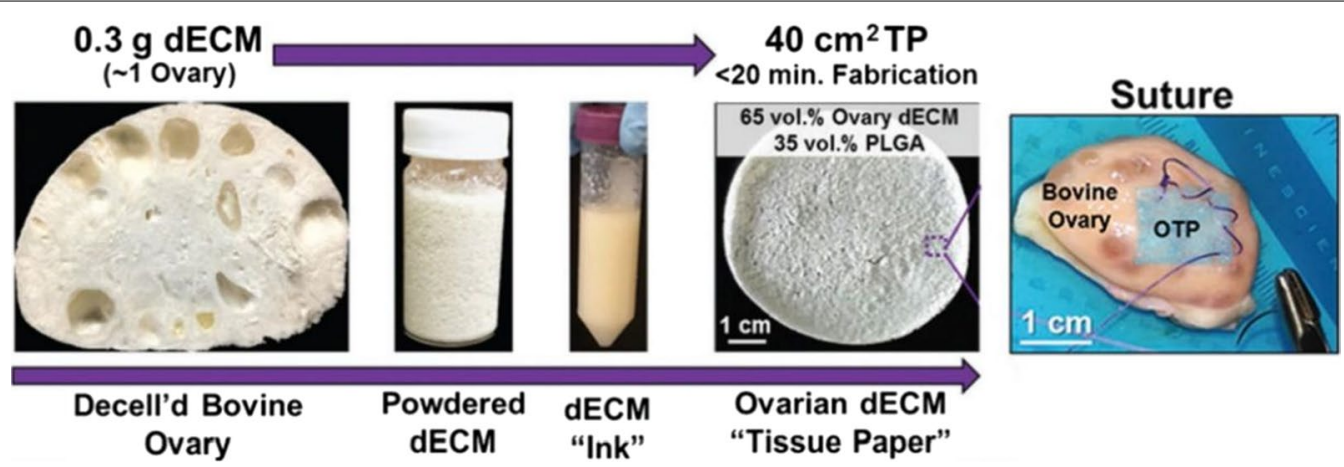

Fig. 5 Re-transplantation of"tissue paper" made from bovine ovarian dECM tissue. Reproduced with permission from [116]

indicating that the application of the $\mathrm{dECM}$ was a promising strategy for the regeneration of epithelium and myometrium in the uterus [66]. Pregnancy was even reported in another study that transplanted $\mathrm{dECM}$ scaffolds recellularized with endometrial and myometrial primary cells to repair native rat uterine tissue defects in vivo [55]. Similarly, collagen scaffolds layered with human umbilical cord-derived mesenchymal stem cells have been used 
to reconstruct endometrium and preserve fertility in an induced murine uterine defect model [13]. In addition, a whole porcine uterus has been decellularized while maintaining the vascular network and preserving the dECM (Fig. 6). These researchers also successfully recellularized the small acellular disk scaffolds with human side population stem cells [56].

\subsection{Cervicovaginal tissue engineering using collagen-based biomaterials}

The vaginal matrix is composed of various proteins such as collagen, microfibrils, and elastin. Treatment of congenital absence of the vagina, vaginal deformity, and acquired vaginal trauma have been challenging owing to the lack of compatible and useful biomaterials. Autologous tissues such as bladder mucosa and full-thickness skin grafts have been used in vaginal reconstruction. However, extra trauma caused by obtaining autologous tissue is a significant issue for patients. The development of artificial materials such as engineered acellular intestinal submucosa segments [12], collagen, or dECM layered scaffolds [109] provides promising solutions. Engineered scaffold with the commercial name ADM (QingYuan WeiYe Biotech, Beijing, China) that is layered with critical dECM components containing collagen, elastin, and proteoglycans has been applied to 53 patients with Mayer-Rokitansky-Küster-Hauser (MRKH) syndrome, a disease of congenital absence of the uterus and vagina. As a result, follow-up showed near-normal sexual function and satisfaction for all patients [103]. Acellular porcine small intestinal submucosa (SIS), which is primarily composed of non-crosslinked collagen, glycosaminoglycans, proteoglycans, and glycoproteins [118], has also been successfully applied to 8 patients with cervicovaginal agenesis or dysgenesis and 2 patients with
MRKH syndrome [104, 105]. The collagen-based materials showed superior biocompatibility and did not produce immunologic rejection during the application. In addition, it spared patients from the additional trauma of traditional reconstruction through autologous tissues vaginoplasty. Moreover, collagen-based electrospun materials have been applied to tissue engineering and wound healing. Electrospinning of type I collagen scaffolds leads to similar materials to native dermal ECM that are capable of supporting angiogenesis and epithelialization, and show greater resistance to tissue contraction, which makes them promising for vaginal reconstruction [119].

\subsection{Pelvic reconstruction using collagen-based biomaterials}

It is estimated that more than $25 \%$ of women suffer from POP, a disease defined as the herniation or descent of pelvic organs into the vagina, of which the estimated lifetime risk of surgery is about 19\% [120]. Synthetic polypropylene (PP) meshes have been widely applied in POP reconstructive surgery. However, this risks adverse events such as foreign body tissue response, chronic pain, tissue contracture, and mesh exposure. To minimize adverse effects, numerous studies have designed collagen coatings to modify PP mesh. For example, less erosion and inflammation were reported when coating the PP mesh with acellular porcine collagen, which could decrease mesh tissue adhesion to the surgical wound, prevent severe initial inflammatory response, and diminish the risk of chronic pain and mesh exposure [109, 110]. In addition, ECM coating can be applied to improve the biocompatibility of mesh owing to its degradable properties, which facilitate wound tissue remodeling and tissue formation rather than tissue fibrosis [111]. In
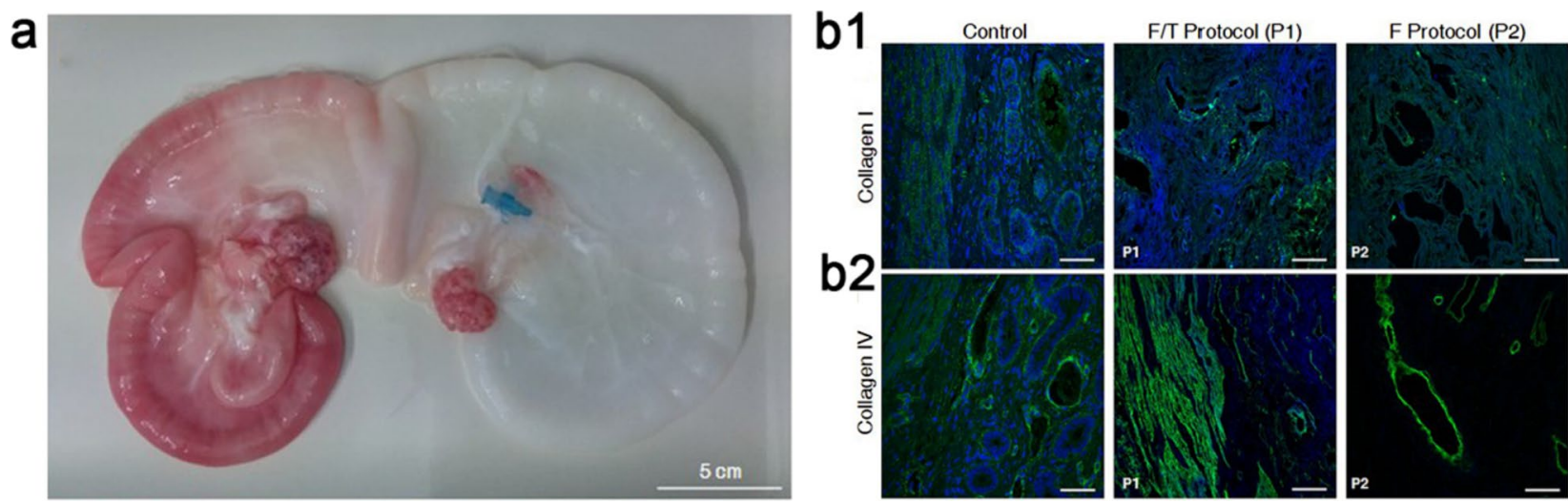

Fig. $\mathbf{6} \mathrm{dECM}$ of porcine uterus. a Macroscopic picture of porcine uterine horns after decellularization (DC). b1, b2 Immunofluorescence staining of collagen I (green signal of b1) and collagen IV (green signal of b2) after DC. (Control: uterus before DC. P1: freeze/thawed samples after DC. P2: Fresh samples after DC). Reproduced with permission from [56] 
addition, PP materials coated with collagen type I and III were reported to facilitate the adhesion and proliferation of human urothelial cells, which is promising in the application of urethral reconstruction [121]. However, mesh erosion is still a difficult problem since PP mesh is non-degradable. Therefore, a biodegradable, more biocompatible biomaterial is in urgent need. Recently, an electrospun polycaprolactone resorbable mesh showed no erosion in an ovine model [122]. Inspired by the successful application of collagen-based electrospun materials in skin tissue and musculoskeletal engineering, we hypothesize that collagen-based electrospinning is promising for improving biocompatibility and biodegradability in pelvic reconstruction.

\subsection{Regenerative medicine using placenta ECM}

The placenta contains an abundance of ECM and is relatively easy to acquire as stem/progenitor cells are discarded after delivery. It is assumed that placenta ECM represents a valuable resource for regenerative medicine, especially for tissue engineering, because of its ample bioactive molecules essential for regeneration [102]. However, the application of placental ECM is still in its infancy.

\section{Discussion}

Reproductive medicine, especially human fertility preservation strategies and reproductive organ regeneration, has gathered increasing attention because of the aging populations seen globally. Collagen, a renewable resource with a wide range of sources, provides an ideal choice for solving clinical problems in regenerative medicine. The principles of leather manufacturing can inspire resolving the current challenges in the engineering of collagenbased regenerative materials. Moreover, the chemistry of leather tanning may also provide a guideline in the fundamental design of regenerative materials to better meet clinical requirements in regenerative medicine.

\subsection{Tanning chemistry-based inspiration}

The mechanism of leather tanning can inspire the engineering of materials with strong mechanical properties. One of the most serious shortcomings of collagen-based biomaterials is that the weak mechanical properties result in the loss of the collagen porous structure. This property makes it impossible for current collagen-based materials to truly replace the ECM to support cell growth and other functions. The leather manufacturing process is the process of enhancing the mechanical properties of leather and maintaining the collagen structure. This suggests that through a similar process to leather manufacturing, the mechanical properties of collagen could be improved while ensuring the physiological activity to ensure that collagen-based biomaterials can better meet the needs of regenerative medicine.

In addition, the metal-tannin combination process can impart multiple functions to biomaterials due to the coordination property of polyphenols (tannins). Metalphenol networks (MPNs) have been widely used in biomedical research, and have shown great application potential in the fields of drug-controlled release and cell interface engineering. The shortcomings of cytokines, DNA drugs, and RNA drugs are that they are easily degraded and inactivated, which limit their application in the field of reproduction. Therefore, designing specific metal polyphenol-containing collagen-based biomaterials according to clinical needs is expected to further expand the application range of collagen materials in the field of reproductive medicine.

\subsection{Collagen-based soft electronic materials}

Collagen-based biomaterials show unique advantages, such as superior biocompatibility and biodegradability, potentially useful for preparing soft electronic materials. Health monitoring has a wide range of applications in reproductive medicine. Collagen-based soft electronic materials, therefore, have great application prospects in the field of health monitoring.

\subsection{Fertility preservation strategies and hormone replacement therapy (HRT) perspectives}

Re-transplantation after cryopreservation of ovarian tissue is the only option to preserve fertility in prepubertal females and patients who require immediate cancer treatment. However, the initial tissue ischemia after re-transplantation is also a problem that plagues physicians. Collagen-based tissue engineering provides a new perspective in aiding the initial revascularization process and the isolation of malignant cells in ovary re-transplantation. Artificial collagen-based biomaterials that encapsulate ovarian follicles with hormone secretion functions are expected to serve as a more precise HRT, which is expected to be much closer to the natural female physiological state and with fewer side effects.

\subsection{Tissue regeneration, organ reconstruction, and artificial uterus perspectives}

One of the most promising new frontiers in current medicine is regenerative medicine. It is hoped that in the future, the development of engineered tissue can provide fewer adverse reactions such as rejection, tissue contracture, and scar hyperplasia. Moreover, the regeneration of nerve cells in engineered tissue is promising for regaining sexual sensation for patients suffering from congenital absence of the vagina, vaginal deformity, and acquired vaginal trauma. Also, a 
tissue-engineered artificial uterus provides hope to patients suffering from uterine infertility.

\section{Conclusion}

In this review, we introduced the collagen-based materials used in reproductive medicine, including collagen hydrogel scaffolds, decellularized ECM, and collagenbased bioinks. Additionally, five current applications of collagen-based biomaterials (i.e., ovarian tissue engineering, uterine tissue engineering, cervicovaginal tissue engineering, pelvic reconstruction, and placenta ECM) were reviewed comprehensively. Finally, we discussed the relationship between the exploration of collagen-based materials used in reproductive medicine and the leather industry. This review will hopefully provide integrated knowledge and interesting perspectives for researchers committed to conducting cutting-edge studies and promoting the development of artificial materials in reproductive medicine.

\begin{abstract}
Abbreviations
ECM: Extracellular matrix; dECM: Decellularized ECM; IVF: In vitro fertilization; ICSI: Intracytoplasmic sperm injection; IVM: In vitro maturation; Gly: Glycine; Pro: Proline; Hyp: Hydroxyproline; 3D: Three-dimensional; 2D: Two-dimensional; Pue@GelMA: Pue-loaded gelatin methacrylate; POP: Pelvic organ prolapse; CDI: Carbodiimide; HMDC: Hexamethylene diamine carbamate; GP: Genipin; PC: Proanthocyanins; NDGA: Nordihydroguaiaretic acid; iPSC: Induced pluripotent stem cell; MSC:: Mesenchymal stem cell; AVM:: Acellular vagina matrix; Col:: Collagen; Alg:: Alginate; O-alg:: Oxidized-alginate; PAS:: Periodic acid-Schiff; DAPI:: 4',6-Diamidino-2-phenylindole; DC:: Decellularization; MRKH:: Mayer-Rokitansky-Küster-Hauser; SIS:y: Small intestinal submucosa; PP:.: Polypropylene; VEGF:: Vascular endothelial growth factor; MPN:: Metal-phenol network; HRT:: Hormone replacement therapy.
\end{abstract}

\section{Acknowledgements}

We thank Meifeng Li for the useful discussion.

\section{Authors' contributions}

$Y Z$, JG, and LQ made substantial contributions to the conception and design of this review. HC, LX, and GG wrote the manuscript. JP and XW participated in the design of figures in this review. All authors read and approved the final manuscript.

\section{Funding}

The work in the L.Q. laboratory was financially supported by the Sichuan Science and Technology Program (L.Q., Grant No. 2020YFS0127). The work in the Y.Z. laboratory was financially supported by the Research project of Science \& Technology Department of Sichuan Province (Y.Z., Grant No. 2021YJ0416), project of Chengdu Science and Technology Bureau, (Y.Z., Grant No. 2021-YF05-02110-SN) National Natural Science Foundation of China (Y.Z., Grant No. 82001496), China Postdoctoral Science Foundation (Y.Z., Grant No. 2020M680149, 2020T130087ZX). The work in the J.G. laboratory was financially supported by the National Global Talents Recruitment Program (J.G.), National Natural Science Foundation of China (22178233), Talents Program of Sichuan Province, Double First Class University Plan of Sichuan University, State Key Laboratory of Polymer Materials Engineering (J.G., Grant No. sklpme 2020-3-01).

\section{Availability of data and materials}

The datasets analyzed in this review are available as quoted and listed in the "References" section which have been specified in the article.

\section{Declarations}

Competing interests

The authors declare no competing interests.

\section{Author details}

${ }^{1}$ Department of Obstetrics and Gynecology, The Reproductive Medical Center, West China Second University Hospital, Sichuan University, Chengdu 610041, China. ${ }^{2}$ Key Laboratory of Birth Defects and Related of Women and Children of Ministry of Education, West China Second University Hospital, Sichuan University, Chengdu 610041, China. ${ }^{3}$ West China School of Medicine, Sichuan University, Chengdu 610041, China. ${ }^{4}$ BMI Center for Biomass Materials and Nanointerfaces, College of Biomass Science and Engineering, Sichuan University, Chengdu 610065, Sichuan, China. ${ }^{5}$ State Key Laboratory of Polymer Materials Engineering, Sichuan University, Chengdu 610065, Sichuan, China.

Received: 28 June 2021 Accepted: 10 November 2021

Published online: 15 January 2022

References

1. Wise WR, Covington A. Tanning chemistry: the science of leather, 2nd edn. 2019.

2. Roseti L, Cavallo C, Desando G, Parisi V, Petretta M, Bartolotti I, et al. Three-dimensional bioprinting of cartilage by the use of stem cells: A strategy to improve regeneration. Materials (Basel, Switzerland). 2018:11(9):1749. https://doi.org/10.3390/ma11091749.

3. Ricard-Blum S. The collagen family. Cold Spring Harb Perspect Biol. 2011;3(1):a004978. https://doi.org/10.1101/cshperspect.a004978.

4. Glowacki J, Mizuno S. Collagen scaffolds for tissue engineering. Biopolymers. 2008;89(5):338-44. https://doi.org/10.1002/bip.20871.

5. Vander Borght M, Wyns C. Fertility and infertility: definition and epidemiology. Clin Biochem. 2018;62:2-10. https://doi.org/10.1016/j.clinb iochem.2018.03.012.

6. Steptoe PC, Edwards RG. Birth after the reimplantation of a human embryo. Lancet. 1978;2(8085):366. https://doi.org/10.1016/s01406736(78)92957-4.

7. Chen C. Pregnancy after human oocyte cryopreservation. Lancet. 1986;1 (8486):884-6. https://doi.org/10.1016/s0140-6736(86)90989-x.

8. Palermo G, Joris H, Devroey P, Van Steirteghem AC. Pregnancies after intracytoplasmic injection of single spermatozoon into an oocyte. Lancet. 1992;340(8810):17-8. https://doi.org/10.1016/0140-6736(92) 92425-f.

9. Trounson A, Wood C, Kausche A. In vitro maturation and the fertilization and developmental competence of oocytes recovered from untreated polycystic ovarian patients. Fertil Steril. 1994;62(2):353-62. https://doi. org/10.1016/s0015-0282(16)56891-5.

10. Oktay K, Karlikaya G. Ovarian function after transplantation of frozen, banked autologous ovarian tissue. N Engl J Med. 2000;342(25):1919. https://doi.org/10.1056/nejm200006223422516.

11. Jones BP, Saso S, Bracewell-Milnes T, Thum MY, Nicopoullos J, DiazGarcia C, et al. Human uterine transplantation: a review of outcomes from the first 45 cases. BJOG Int J Obstet Gynaecol. 2019;126(11):13109. https://doi.org/10.1111/1471-0528.15863.

12. Raya-Rivera AM, Esquiliano D, Fierro-Pastrana R, López-Bayghen E, Valencia P, Ordorica-Flores R, et al. Tissue-engineered autologous vaginal organs in patients: a pilot cohort study. Lancet. 2014;384(9940):32936. https://doi.org/10.1016/s0140-6736(14)60542-0.

13. Xin L, Lin X, Pan Y, Zheng X, Shi L, Zhang Y, et al. A collagen scaffold loaded with human umbilical cord-derived mesenchymal stem cells facilitates endometrial regeneration and restores fertility. Acta Biomater. 2019;92:160-71. https://doi.org/10.1016/j.actbio.2019.05.012.

14. Divakar P, Trembly BS, Moodie KL, Hoopes PJ, Wegst UGK. Preliminary assessment of a hysteroscopic fallopian tube heat and biomaterial technology for permanent female sterilization. Proc SPIE Int Soc Opt Eng. 2017. https://doi.org/10.1117/12.2255843.

15. Subramanian B, Rameshbabu AP, Ghosh K, Jha PK, Jha R, Murugesan $\mathrm{S}$, et al. Impact of styrene maleic anhydride (SMA) based hydrogel on rat fallopian tube as contraceptive implant with selective 
antimicrobial property. Mater Sci Eng C Mater Biol Appl. 2019;94:94107. https://doi.org/10.1016/.msec.2018.09.023.

16. Sorushanova A, Delgado LM, Wu Z, Shologu N, Kshirsagar A Raghunath $\mathrm{R}$, et al. The collagen suprafamily: from biosynthesis to advanced biomaterial development. Adv Mater. 2019;31(1):e1801651. https://doi.org/10.1002/adma.201801651.

17. Kadler KE, Holmes DF, Trotter JA, Chapman JA. Collagen fibril formation. Biochem J. 1996;316:1-11. https://doi.org/10.1042/bj3160001.

18. Ferreira AM, Gentile P, Chiono V, Ciardelli G. Collagen for bone tissue regeneration. Acta Biomater. 2012;8(9):3191-200. https://doi.org/10. 1016/j.actbio.2012.06.014.

19. Walimbe T, Panitch A. Best of both hydrogel worlds: harnessing bioactivity and tunability by incorporating glycosaminoglycans in collagen hydrogels. Bioengineering (Basel). 2020. https://doi.org/10. 3390/bioengineering7040156.

20. Caliari SR, Burdick JA. A practical guide to hydrogels for cell culture. Nat Methods. 2016;13(5):405-14. https://doi.org/10.1038/nmeth. 3839.

21. Liu H, Wang Y, Cui K, Guo Y, Zhang X, Qin J. Advances in hydrogels in organoids and organs-on-a-chip. Adv Mater. 2019;31(50):e1902042. https://doi.org/10.1002/adma.201902042.

22. Sarrigiannidis SO, Rey JM, Dobre O, González-García C, Dalby MJ, Salmeron-Sanchez M. A tough act to follow: collagen hydrogel modifications to improve mechanical and growth factor loading capabilities. Mater Today Bio. 2021;10:100098. https://doi.org/10. 1016/j.mtbio.2021.100098.

23. Ghorbani M, Ai J, Nourani MR, Azami M, Hashemi Beni B, Asadpour $S$, et al. Injectable natural polymer compound for tissue engineering of intervertebral disc: In vitro study. Mater Sci Eng C Mater Biol Appl. 2017;80:502-8. https://doi.org/10.1016/j.msec.2017.06.007.

24. Krych AJ, Wanivenhaus F, Ng KW, Doty S, Warren RF, Maher SA. Matrix generation within a macroporous non-degradable implant for osteochondral defects is not enhanced with partial enzymatic digestion of the surrounding tissue: evaluation in an in vivo rabbit model. J Mater Sci Mater Med. 2013;24(10):2429-37. https://doi.org/10.1007/ s10856-013-4999-x.

25. Geanaliu-Nicolae RE, Andronescu E. Blended natural support materials-collagen based hydrogels used in biomedicine. Materials (Basel). 2020. https://doi.org/10.3390/ma13245641.

26. Lou J, Stowers R, Nam S, Xia Y, Chaudhuri O. Stress relaxing hyaluronic acid-collagen hydrogels promote cell spreading, fiber remodeling, and focal adhesion formation in 3D cell culture. Biomaterials. 2018;154:213-22. https://doi.org/10.1016/j.biomaterials.2017.11.004.

27. Bao Z, Gao M, Fan X, Cui Y, Yang J, Peng X, et al. Development and characterization of a photo-cross-linked functionalized type-I collagen (Oreochromis niloticus) and polyethylene glycol diacrylate hydrogel. Int J Biol Macromol. 2020;155:163-73. https://doi.org/10. 1016/j.ijbiomac.2020.03.210.

28. Patel B, Xu Z, Pinnock CB, Kabbani LS, Lam MT. Self-assembled collagen-fibrin hydrogel reinforces tissue engineered adventitia vessels seeded with human fibroblasts. Sci Rep. 2018;8(1):3294. https:// doi.org/10.1038/s41598-018-21681-7.

29. Echave MC, Sánchez P, Pedraz JL, Orive G. Progress of gelatin-based 3D approaches for bone regeneration. J Drug Deliv Sci Technol. 2017:42:63-74. https://doi.org/10.1016/j.jddst.2017.04.012.

30. Yue K, Trujillo-de Santiago G, Alvarez MM, Tamayol A, Annabi N, Khademhosseini A. Synthesis, properties, and biomedical applications of gelatin methacryloyl (GelMA) hydrogels. Biomaterials. 2015;73:254-71. https://doi.org/10.1016/j.biomaterials.2015.08.045.

31. Vanaei S, Parizi MS, Vanaei S, Salemizadehparizi F, Vanaei HR. An overview on materials and techniques in $3 \mathrm{D}$ bioprinting toward biomedical application. Eng Regener. 2021;2:1-18. https://doi.org/10. 1016/j.engreg.2020.12.001.

32. Schutte SC, Taylor RN. A tissue-engineered human endometrial stroma that responds to cues for secretory differentiation, decidualization, and menstruation. Fertil Steril. 2012;97(4):997-1003. https:// doi.org/10.1016/j.fertnstert.2012.01.098.

33. Joo S, Oh SH, Sittadjody S, Opara EC, Jackson JD, Lee SJ, et al. The effect of collagen hydrogel on 3D culture of ovarian follicles. Biomed Mater. 2016;11(6):065009. https://doi.org/10.1088/1748-6041/11/6/065009.
34. Qin M, Jin J, Saiding Q, Xiang Y, Wang Y, Sousa F, et al. In situ inflammatory-regulated drug-loaded hydrogels for promoting pelvic floor repair. J Control Release. 2020;322:375-89. https://doi.org/10.1016/j.jconrel. 2020.03.030.

35. Su J, Ding L, Cheng J, Yang J, Li X, Yan G, et al. Transplantation of adipose-derived stem cells combined with collagen scaffolds restores ovarian function in a rat model of premature ovarian insufficiency. Hum Reprod. 2016;31(5):1075-86. https://doi.org/10.1093/humrep/dew041.

36. Mehdinia Z, Ashrafi M, Fathi R, Taheri P, Valojerdi MR. Restoration of estrous cycles by co-transplantation of mouse ovarian tissue with MSCs. Cell Tissue Res. 2020;381(3):509-25. https://doi.org/10.1007/ s00441-020-03204-X.

37. Valiente-Alandi I, Schafer AE, Blaxall BC. Extracellular matrix-mediated cellular communication in the heart. J Mol Cell Cardiol. 2016;91:228-37. https://doi.org/10.1016/j.yjmcc.2016.01.011.

38. Ge F, Lu Y, Li Q, Zhang X. Decellularized extracellular matrices for tissue engineering and regeneration. Adv Exp Med Biol. 2020;1250:15-31. https://doi.org/10.1007/978-981-15-3262-7_2.

39. Yao Q, Zheng YW, Lan QH, Kou L, Xu HL, Zhao YZ. Recent development and biomedical applications of decellularized extracellular matrix biomaterials. Mater Sci Eng C Mater Biol Appl. 2019;104:109942. https:// doi.org/10.1016/j.msec.2019.109942

40. Ma B, Wang X, Wu C, Chang J. Crosslinking strategies for preparation of extracellular matrix-derived cardiovascular scaffolds. Regen Biomater. 2014;1 (1):81-9. https://doi.org/10.1093/rb/rbu009.

41. Feng X, Hou X, Cui C, Sun S, Sadik S, Wu S, et al. Mechanical and antibacterial properties of tannic acid-encapsulated carboxymethyl chitosan/polyvinyl alcohol hydrogels. Eng Regener. 2021;2:57-62. https:// doi.org/10.1016/j.engreg.2021.05.002.

42. Boso D, Maghin E, Carraro E, Giagante M, Pavan P, Piccoli M. Extracellular matrix-derived hydrogels as biomaterial for different skeletal muscle tissue replacements. Materials (Basel). 2020. https://doi.org/10.3390/ ma13112483.

43. Nikniaz H, Zandieh Z, Nouri M, Daei-Farshbaf N, Aflatoonian R, Gholipourmalekabadi M, et al. Comparing various protocols of human and bovine ovarian tissue decellularization to prepare extracellular matrix-alginate scaffold for better follicle development in vitro. BMC Biotechnol. 2021;21(1):8. https://doi.org/10.1186/s12896-020-00658-3.

44. Mayorca-Guiliani AE, Willacy O, Madsen CD, Rafaeva M, Elisabeth Heumüller S, Bock F, et al. Decellularization and antibody staining of mouse tissues to map native extracellular matrix structures in 3D. Nat Protoc. 2019:14(12):3395-425. https://doi.org/10.1038/s41596-019-0225-8.

45. Alshaikh AB, Padma AM, Dehlin M, Akouri R, Song MJ, Brännström M, et al. Decellularization and recellularization of the ovary for bioengineering applications; studies in the mouse. Reprod Biol Endocrinol. 2020;18(1):75. https://doi.org/10.1186/s12958-020-00630-y.

46. Alshaikh AB, Padma AM, Dehlin M, Akouri R, Song MJ, Brannstrom M, et al. Decellularization of the mouse ovary: comparison of different scaffold generation protocols for future ovarian bioengineering. J Ovarian Res. 2019;12(1):58. https://doi.org/10.1186/s13048-019-0531-3.

47. Eivazkhani F, Abtahi NS, Tavana S, Mirzaeian L, Abedi F, Ebrahimi B, et al. Evaluating two ovarian decellularization methods in three species. Mater Sci Eng C Mater Biol Appl. 2019;102:670-82. https://doi.org/10. 1016/j.msec.2019.04.092.

48. Pors SE, Ramløse M, Nikiforov D, Lundsgaard K, Cheng J, Andersen CY, et al. Initial steps in reconstruction of the human ovary: survival of preantral stage follicles in a decellularized human ovarian scaffold. Hum Reprod. 2019;34(8):1523-35. https://doi.org/10.1093/humrep/dez077.

49. Laronda MM, Jakus AE, Whelan KA, Wertheim JA, Shah RN, Woodruff TK. Initiation of puberty in mice following decellularized ovary transplant. Biomaterials. 2015;50:20-9. https://doi.org/10.1016/j.biomaterials.2015. 01.051

50. Mirzaeian L, Eivazkhani F, Hezavehei M, Moini A, Esfandiari F, Valojerdi $M R$, et al. Optimizing the cell seeding protocol to human decellularized ovarian scaffold: application of dynamic system for bio-engineering. Cell J. 2020;22(2):227-35. https://doi.org/10.22074/celli.2020.6604.

51. Henning NF, LeDuc RD, Even KA, Laronda MM. Proteomic analyses of decellularized porcine ovaries identified new matrisome proteins and spatial differences across and within ovarian compartments. Sci Rep. 2019;9(1):20001. https://doi.org/10.1038/s41598-019-56454-3. 
52. Pennarossa G, Ghiringhelli M, Gandolfi F, Brevini TAL. Whole-ovary decellularization generates an effective 3D bioscaffold for ovarian bioengineering. J Assist Reprod Genet. 2020;37(6):1329-39. https://doi. org/10.1007/s10815-020-01784-9.

53. Liu WY, Lin SG, Zhuo RY, Xie YY, Pan W, Lin XF, et al. Xenogeneic decellularized scaffold: a novel platform for ovary regeneration. Tissue Eng Part C Methods. 2017;23(2):61-71. https://doi.org/10.1089/ten.TEC.2016. 0410

54. Santoso EG, Yoshida K, Hirota Y, Aizawa M, Yoshino O, Kishida A, et al. Application of detergents or high hydrostatic pressure as decellularization processes in uterine tissues and their subsequent effects on in vivo uterine regeneration in murine models. PLoS ONE. 2014;9(7):e103201. https://doi.org/10.1371/journal.pone.0103201.

55. Hellstrom M, Moreno-Moya JM, Bandstein S, Bom E, Akouri RR, Miyazaki $\mathrm{K}$, et al. Bioengineered uterine tissue supports pregnancy in a rat model. Fertil Steril. 2016;106(2):487-96.e1. https://doi.org/10.1016/j.fertn stert.2016.03.048.

56. Campo H, Baptista PM, López-Pérez N, Faus A, Cervelló I, Simón C. Deand recellularization of the pig uterus: a bioengineering pilot study. Biol Reprod. 2017;96(1):34-45. https://doi.org/10.1095/biolreprod.116. 143396.

57. Olalekan SA, Burdette JE, Getsios S, Woodruff TK, Kim JJ. Development of a novel human recellularized endometrium that responds to a 28-day hormone treatment. Biol Reprod. 2017;96(5):971-81. https://doi. org/10.1093/biolre/iox039.

58. Daryabari SS, Kajbafzadeh AM, Fendereski K, Ghorbani F, Dehnavi M, Rostami M, et al. Development of an efficient perfusion-based protocol for whole-organ decellularization of the ovine uterus as a human-sized model and in vivo application of the bioscaffolds. J Assist Reprod Genet. 2019;36(6):1211-23. https://doi.org/10.1007/ s10815-019-01463-4.

59. Yao Q, Zheng YW, Lin HL, Lan QH, Huang ZW, Wang LF, et al. Exploiting crosslinked decellularized matrix to achieve uterus regeneration and construction. Artif Cells Nanomed Biotechnol. 2020;48(1):218-29. https://doi.org/10.1080/21691401.2019.1699828.

60. López-Martínez S, Campo H, de Miguel-Gómez L, Faus A, Navarro AT, Díaz A, et al. A natural xenogeneic endometrial extracellular matrix hydrogel toward improving current human in vitro models and future in vivo applications. Front Bioeng Biotechnol. 2021;9:639688. https:// doi.org/10.3389/fbioe.2021.639688.

61. Miki F, Maruyama T, Miyazaki K, Takao T, Yoshimasa Y, Katakura S, et al. The orientation of a decellularized uterine scaffold determines the tissue topology and architecture of the regenerated uterus in ratst. Biol Reprod. 2019;100(5):1215-27. https://doi.org/10.1093/biolre/ioz004.

62. Miyazaki K, Maruyama T. Partial regeneration and reconstruction of the rat uterus through recellularization of a decellularized uterine matrix. Biomaterials. 2014;35(31):8791-800. https://doi.org/10.1016/j.bioma terials.2014.06.052.

63. Padma AM, Tiemann TT, Alshaikh AB, Akouri R, Song MJ, Hellström M. Protocols for rat uterus isolation and decellularization: applications for uterus tissue engineering and 3D cell culturing. Methods $\mathrm{Mol}$ Biol. 2018;1577:161-75. https://doi.org/10.1007/7651_2017_60.

64. Li X, Wang Y, Ma R, Liu X, Song B, Duan Y, et al. Reconstruction of functional uterine tissues through recellularizing the decellularized rat uterine scaffolds by MSCs in vivo and in vitro. Biomed Mater. 2021;16(3):035023. https://doi.org/10.1088/1748-605X/abd116.

65. Li X, Wang Y, Ma R, Liu X, Song B, Duan Y, et al. Reconstruction of functional uterine tissues through recellularizing the decellularized rat uterine scaffolds by MSCsin vivoandin vitro. Biomed Mater. 2020 https://doi.org/10.1088/1748-605X/abd116.

66. Hiraoka T, Hirota Y, Saito-Fujita T, Matsuo M, Egashira M, Matsumoto $L$, et al. STAT3 accelerates uterine epithelial regeneration in a mouse model of decellularized uterine matrix transplantation. JCl Insight. 2016. https://doi.org/10.1172/jci.insight.87591.

67. Campo H, García-Domínguez X, López-Martínez S, Faus A, Vicente Antón JS, Marco-Jiménez F, et al. Tissue-specific decellularized endometrial substratum mimicking different physiological conditions influences in vitro embryo development in a rabbit model. Acta Biomater. 2019;89:126-38. https://doi.org/10.1016/j.actbio.2019.03.004.
68. Leonel L, Miranda C, Coelho TM, Ferreira GAS, Caãada RR, Miglino MA, et al. Decellularization of placentas: establishing a protocol. Braz J Med Biol Res. 2017;51(1):e6382. https://doi.org/10.1590/1414-431×20176382.

69. Shakouri-Motlagh A, Khanabdali R, Heath DE, Kalionis B. The application of decellularized human term fetal membranes in tissue engineering and regenerative medicine (TERM). Placenta. 2017;59:124-30. https:// doi.org/10.1016/j.placenta.2017.07.002.

70. Barreto RS, Romagnolli P, Fratini P, Mess AM, Miglino MA. Mouse placental scaffolds: a three-dimensional environment model for recellularization. J Tissue Eng. 2019;10:2041731419867962. https://doi.org/10.1177/ 2041731419867962.

71. Guvendiren M, Molde J, Soares RMD, Kohn J. Designing Biomaterials for 3D Printing. ACS Biomater Sci Eng. 2016;2(10):1679-93. https://doi.org/ 10.1021/acsbiomaterials.6b00121.

72. Xie Z, Gao M, Lobo AO, Webster TJ. 3D bioprinting in tissue engineering for medical applications: the classic and the hybrid. Polymers. 2020;12(8):1717. https://doi.org/10.3390/polym12081717.

73. Oksdath Mansilla M, Salazar-Hernandez C, Perrin SL, Scheer KG, Cildir G, Toubia J, et al. 3D-printed microplate inserts for long term high-resolution imaging of live brain organoids. BMC Biomed Eng. 2021;3(1):6. https://doi.org/10.1186/s42490-021-00049-5.

74. Xing F, Xiang Z, Rommens PM, Ritz U. 3D Bioprinting for vascularized tissue-engineered bone fabrication. Materials (Basel, Switzerland). 2020;13(10):2278. https://doi.org/10.3390/ma13102278.

75. Zhang YS, Oklu R, Dokmeci MR, Khademhosseini A. Three-dimensional bioprinting strategies for tissue engineering. Cold Spring Harb Perspect Med. 2018;8(2):a025718. https://doi.org/10.1101/cshperspect.a025718.

76. Dzobo K, Motaung K, Adesida A. Recent trends in decellularized extracellular matrix bioinks for 3D printing: an updated review. Int J Mol Sci. 2019. https://doi.org/10.3390/ijms20184628.

77. Laronda MM, Rutz AL, Xiao S, Whelan KA, Duncan FE, Roth EW, et al. A bioprosthetic ovary created using 3D printed microporous scaffolds restores ovarian function in sterilized mice. Nat Commun. 2017:8:15261. https://doi.org/10.1038/ncomms15261.

78. Ji W, Hou B, Lin W, Wang L, Zheng W, Li W, et al. 3D Bioprinting a human iPSC-derived MSC-loaded scaffold for repair of the uterine endometrium. Acta Biomater. 2020;1 16:268-84. https://doi.org/10.1016/j.actbio. 2020.09.012.

79. Hou C, Zheng J, Li Z, Qi X, Tian Y, Zhang M, et al. Printing 3D vagina tissue analogues with vagina decellularized extracellular matrix bioink. Int J Biol Macromol. 2021;180:177-86. https://doi.org/10.1016/j.ijbiomac. 2021.03.070

80. Kuo C-Y, Shevchuk M, Opfermann J, Guo T, Santoro M, Fisher JP, et al. Trophoblast-endothelium signaling involves angiogenesis and apoptosis in a dynamic bioprinted placenta model. Biotechnol Bioeng. 2019;116(1):181-92. https://doi.org/10.1002/bit.26850.

81. Xu M, Kreeger PK, Shea LD, WoodruffTK. Tissue-engineered follicles produce live, fertile offspring. Tissue Eng. 2006;12(10):2739-46. https:// doi.org/10.1089/ten.2006.12.2739.

82. Xiao S, Zhang J, Romero MM, Smith KN, Shea LD, Woodruff TK. In vitro follicle growth supports human oocyte meiotic maturation. Sci Rep. 2015;5:17323. https://doi.org/10.1038/srep17323.

83. West ER, Shea LD, Woodruff TK. Engineering the follicle microenvironment. Semin Reprod Med. 2007;25(4):287-99. https://doi.org/10. 1055/s-2007-980222

84. Amorim CA, Van Langendonckt A, David A, Dolmans MM, Donnez J. Survival of human pre-antral follicles after cryopreservation of ovarian tissue, follicular isolation and in vitro culture in a calcium alginate matrix. Hum Reprod. 2009;24(1):92-9. https://doi.org/10.1093/humrep/ den343.

85. Xu J, Lawson MS, Yeoman RR, Molskness TA, Ting AY, Stouffer RL, et al. Fibrin promotes development and function of macaque primary follicles during encapsulated three-dimensional culture. Hum Reprod. 2013;28(8):2187-200. https://doi.org/10.1093/humrep/det093.

86. Desai N, Abdelhafez F, Calabro A, Falcone T. Three dimensional culture of fresh and vitrified mouse pre-antral follicles in a hyaluronan-based hydrogel: a preliminary investigation of a novel biomaterial for in vitro follicle maturation. Reprod Biol Endocrinol. 2012;10(1):29. https://doi. org/10.1186/1477-7827-10-29.

87. Zhou H, Malik MA, Arab A, Hill MT, Shikanov A. Hydrogel based 3-dimensional (3D) system for toxicity and high-throughput 
(HTP) analysis for cultured murine ovarian follicles. PLOS ONE. 2015;10(10):e0140205. https://doi.org/10.1371/journal.pone.0140205.

88. Shikanov A, Smith RM, Xu M, Woodruff TK, Shea LD. Hydrogel network design using multifunctional macromers to coordinate tissue maturation in ovarian follicle culture. Biomaterials. 2011;32(10):252431. https://doi.org/10.1016/j.biomaterials.2010.12.027.

89. Amorim CA, Shikanov A. The artificial ovary: current status and future perspectives. Future Oncol. 2016;12(20):2323-32. https://doi.org/10. 2217/fon-2016-0202.

90. Rios PD, Kniazeva E, Lee HC, Xiao S, Oakes RS, Saito E, et al. Retrievable hydrogels for ovarian follicle transplantation and oocyte collection. Biotechnol Bioeng. 2018;115(8):2075-86. https://doi.org/10. 1002/bit.26721

91. Vanacker J, Luyckx V, Dolmans MM, Des Rieux A, Jaeger J, Van Langendonckt A, et al. Transplantation of an alginate-matrigel matrix containing isolated ovarian cells: first step in developing a biodegradable scaffold to transplant isolated preantral follicles and ovarian cells. Biomaterials. 2012;33(26):6079-85. https://doi.org/10.1016/j. biomaterials.2012.05.015.

92. Day JR, David A, Cichon AL, Kulkarni T, Cascalho M, Shikanov A. Immunoisolating poly(ethylene glycol) based capsules support ovarian tissue survival to restore endocrine function. J Biomed Mater Res A. 2018;106(5):1381-9. https://doi.org/10.1002/jbm.a.36338.

93. Felder S, Masasa H, Orenbuch A, Levaot N, Shachar Goldenberg M, Cohen S. Reconstruction of the ovary microenvironment utilizing macroporous scaffold with affinity-bound growth factors. Biomaterials. 2019;205:11-22. https://doi.org/10.1016/j.biomaterials.2019.03. 013.

94. Sittadjody S, Saul JM, McQuilling JP, Joo S, Register TC, Yoo JJ, et al. In vivo transplantation of 3D encapsulated ovarian constructs in rats corrects abnormalities of ovarian failure. Nat Commun. 2017;8(1):1858. https://doi.org/10.1038/s41467-017-01851-3.

95. Meng CX, Andersson KL, Bentin-Ley U, Gemzell-Danielsson K, Lalitkumar PG. Effect of levonorgestrel and mifepristone on endometria receptivity markers in a three-dimensional human endometrial cell culture model. Fertil Steril. 2009;91(1):256-64. https://doi.org/10. 1016/j.fertnstert.2007.11.007.

96. Zambuto SG, Clancy KBH, Harley BAC. A gelatin hydrogel to study endometrial angiogenesis and trophoblast invasion. Interface Focus. 2019:9(5):20190016. https://doi.org/10.1098/rsfs.2019.0016.

97. Kessler M, Hoffmann K, Brinkmann V, Thieck O, Jackisch S, Toelle B, et al. The Notch and Wnt pathways regulate stemness and differentiation in human fallopian tube organoids. Nat Commun. 2015;6:8989. https://doi.org/10.1038/ncomms9989.

98. Crapo PM, Gilbert TW, Badylak SF. An overview of tissue and whole organ decellularization processes. Biomaterials. 2011;32(12):3233-43. https://doi.org/10.1016/j.biomaterials.2011.01.057.

99. Hassanpour A, Talaei-Khozani T, Kargar-Abarghouei E, Razban V, Vojdani Z. Decellularized human ovarian scaffold based on a sodium lauryl ester sulfate (SLES)-treated protocol, as a natural three-dimensional scaffold for construction of bioengineered ovaries. Stem Cell Res Ther. 2018;9(1):252. https://doi.org/10.1186/s13287-018-0971-5.

100. Motamed M, Sadr Z, Valojerdi MR, Moini A, Oryan S, Totonchi M, et al. Tissue engineered human amniotic membrane application in mouse ovarian follicular culture. Ann Biomed Eng. 2017:45(7):1664-75. https://doi.org/10.1007/s10439-017-1836-2.

101. Favaron PO, Borghesi J, Mess AM, Castelucci P, Schiavo Matias GS, Barreto R, et al. Establishment of 3-dimensional scaffolds from hemochorial placentas. Placenta. 2019;81:32-41. https://doi.org/10.1016/j. placenta.2019.04.002.

102. Lobo SE, Leonel LC, Miranda CM, Coelho TM, Ferreira GA, Mess A, et al. The placenta as an organ and a source of stem cells and extracellular matrix: a review. Cells Tissues Organs. 2016;201(4):239-52. https://doi.org/10.1159/000443636.

103. Zhu L, Zhou H, Sun Z, Lou W, Lang J. Anatomic and sexual outcomes after vaginoplasty using tissue-engineered biomaterial graft in patients with Mayer-Rokitansky-Kuster-Hauser syndrome: a new minimally invasive and effective surgery. J Sex Med. 2013;10(6):16528. https://doi.org/10.1111/jsm.12143.

104. Ding JX, Chen XJ, Zhang XY, Zhang Y, Hua KQ. Acellular porcine small intestinal submucosa graft for cervicovaginal reconstruction in eight patients with malformation of the uterine cervix. Hum Reprod. 2014;29(4):677-82. https://doi.org/10.1093/humrep/det470.

105. Ding JX, Zhang XY, Chen LM, Hua KQ. Vaginoplasty using acellular porcine small intestinal submucosa graft in two patients with Meyer-von-Rokitansky-Kuster-Hauser syndrome: a prospective new technique for vaginal reconstruction. Gynecol Obstet Invest. 2013;75(2):93-6. https://doi.org/10.1159/000343233.

106. Li Y, Liu F, Zhang Z, Zhang M, Cao S, Li Y, et al. Bone marrow mesenchymal stem cells could acquire the phenotypes of epithelial cells and accelerate vaginal reconstruction combined with small intestinal submucosa. Cell Biol Int. 2015;39(11):1225-33. https://doi.org/10. 1002/cbin.10495.

107. Kuo CY, Eranki A, Placone JK, Rhodes KR, Aranda-Espinoza H, Fernandes R, et al. Development of a 3D printed, bioengineered placenta model to evaluate the role of trophoblast migration in preeclampsia. ACS Biomater Sci Eng. 2016;2(10):1817-26. https://doi. org/10.1021/acsbiomaterials.6b00031.

108. Paul K, Darzi S, McPhee G, Del Borgo MP, Werkmeister JA, Gargett CE, et al. 3D bioprinted endometrial stem cells on melt electrospun poly epsilon-caprolactone mesh for pelvic floor application promote anti-inflammatory responses in mice. Acta Biomater. 2019;97:162-76. https://doi.org/10.1016/jactbio.2019.08.003.

109. Darzi S, Urbankova I, Su K, White J, Lo C, Alexander D, et al. Tissue response to collagen containing polypropylene meshes in an ovine vaginal repair model. Acta Biomater. 2016;39:114-23. https://doi.org/ 10.1016/j.actbio.2016.05.010.

110. Huffaker RK, Muir TW, Rao A, Baumann SS, Kuehl TJ, Pierce LM. Histologic response of porcine collagen-coated and uncoated polypropylene grafts in a rabbit vagina model. Am J Obstet Gynecol. 2008;198(5):582.e1-7. https://doi.org/10.1016/j.ajog.2007.12.029.

111. Wolf MT, Carruthers CA, Dearth CL, Crapo PM, Huber A, Burnsed OA, et al. Polypropylene surgical mesh coated with extracellular matrix mitigates the host foreign body response. J Biomed Mater Res A. 2014;102(1):234-46. https://doi.org/10.1002/jbm.a.34671.

112. Rivas Leonel EC, Lucci CM, Amorim CA. Cryopreservation of human ovarian tissue: a review. Transfus Med Hemother. 2019;46(3):173-81. https://doi.org/10.1159/000499054.

113. Gargus ES, Rogers HB, McKinnon KE, Edmonds ME, Woodruff TK. Engineered reproductive tissues. Nat Biomed Eng. 2020;4(4):381-93. https://doi.org/10.1038/s41551-020-0525-x.

114. Choi JK, Agarwal P, Huang H, Zhao S, He X. The crucial role of mechanical heterogeneity in regulating follicle development and ovulation with engineered ovarian microtissue. Biomaterials. 2014;35(19):5122-8. https://doi.org/10.1016/j.biomaterials.2014.03. 028.

115. Oktay K, Bedoschi G, Pacheco F, Turan V, Emirdar V. First pregnancies, live birth, and in vitro fertilization outcomes after transplantation of frozen-banked ovarian tissue with a human extracellular matrix scaffold using robot-assisted minimally invasive surgery. Am J Obstet Gynecol. 2016;214(1):94.e1-9. https://doi.org/10.1016/j.ajog.2015.10. 001.

116. Jakus AE, Laronda MM, Rashedi AS, Robinson CM, Lee C, Jordan SW, et al. "Tissue Papers" from organ-specific decellularized extracellular matrices. Adv Funct Mater. 2017. https://doi.org/10.1002/adfm.20170 0992.

117. Kisu I, Banno K, Mihara M, Hara H, Kato Y, Suganuma N, et al. Uterine transplantation in primates: a mini-review of the literature. Transplant Proc. 2014;46(4):1212-6. https://doi.org/10.1016/j.transproceed.2013. 10.046 .

118. Soiderer EE, Lantz GC, Kazacos EA, Hodde JP, Wiegand RE. Morphologic study of three collagen materials for body wall repair. J Surg Res. 2004;118(2):161-75. https://doi.org/10.1016/S0022-4804(03) 00352-4.

119. Cheng L, Wang Y, Sun G, Wen S, Deng L, Zhang H, et al. Hydrationenhanced lubricating electrospun nanofibrous membranes prevent tissue adhesion. Research. 2020;2020:4907185. https://doi.org/10. 34133/2020/4907185.

120. Smith FJ, Holman CD, Moorin RE, Tsokos N. Lifetime risk of undergoing surgery for pelvic organ prolapse. Obstet Gynecol. 2010;116(5):1096-100. https://doi.org/10.1097/AOG.0b013e3181 f73729. 
121. Bisson I, Hilborn J, Wurm F, Meyrat B, Frey P. Human urothelial cells grown on collagen adsorbed to surface-modified polymers. Urology. 2002;60(1):176-80. https://doi.org/10.1016/s0090-4295(02)01642-4.

122. Zakko J, Blum KM, Drews JD, Wu Y-L, Hatoum H, Russell M, et al. Development of tissue engineered heart valves for percutaneous transcatheter delivery in a fetal ovine model. JACC Basic Transl Sci. 2020;5(8):81528. https://doi.org/10.1016/j.jacbts.2020.06.009.

\section{Publisher's Note}

Springer Nature remains neutral with regard to jurisdictional claims in published maps and institutional affiliations.

\section{Submit your manuscript to a SpringerOpen ${ }^{\circ}$ journal and benefit from:}

- Convenient online submission

- Rigorous peer review

- Open access: articles freely available online

- High visibility within the field

- Retaining the copyright to your article

Submit your next manuscript at $\boldsymbol{\nabla}$ springeropen.com 